\title{
Factors Influencing Implementation of Rural Electrification Programme in Kenya: A Case of Kieni East Sub County, Nyeri County
}

\author{
Rosemary Kareithi \\ George Muhua \\ University of Nairobi. Kenya
}

Doi: 10.19044/esj.2018.v14n21p236 URL:http://dx.doi.org/10.19044/esj.2018.v14n21p236

\begin{abstract}
The Government of Kenya through numerous policies and programmes have come up with the rural electrification programmes which is to play a crucial role in the provision of electricity to rural areas in a bid to spur human, social and economic development in the Country. The purpose of this study was to determine the factors influencing the implementation of rural electrification programme in Kieni East Sub County, Nyeri County. The study adopted a descriptive survey research design. The target population of the study was 4289 households and 10 Rural Electrification Authority Team in Kieni East Sub County. Simple random sampling and Purposive sampling was used to select a sample of 94 households and 5 Rural Electrification Authority Officials. The data was collected through structured questionnaires. Reliability of the questionnaires and validity was tested through piloting. Ethics in research was observed and responses were handled with utmost confidentiality, while the study ensured fair gender representation of respondents. The data was analyzed using through descriptives and presented through tables and graphs. The study found that funding, cost of electricity, alternative sources of power and demand affected implementation of Rural Electrification Programme to a great extent. Thus, these factors play a key role in determining the success of the implementation of Rural Electrification Programme in Kieni East Sub County. The study recommended that subsidizing of consumer connections cost, wiring material cost and unit cost of energy should be lowered and also provision of incentives for investments in alternative power sources such as allocation of sufficient funds and timely disbursement for implementation of grid extension in Kieni East should be encouraged by involving policy makers and the government in formulation of policies favorable for the implementation of Rural Electrification Programme in rural areas of Kenya. The study suggests that further studies
\end{abstract}


should be carried out on the influence of institutional factors on the implementation of rural electrification programs in Kenya.

Keywords: Cost, Demand, Implementation, Rural Electrification, Funding, Power

\section{Introduction}

Although literature indicates that rural electrification (RE) is a global phenomenon, 1.3 billion people in the World do not have access to electricity, representing 18 percent of the global population, many of them live in Africa and South Asia. In Africa, rural electrification rate is at 28 percent with North Africa having access rate of 99 percent while Sub Saharan Africa has 18 percent. Rural Electrification Programme was launched in 1973 to support both non-economic and commercial schemes in the rural areas with KPLC acting as the managing agent on behalf of the government. Despite, the substantial progress made towards the realization of sustainable development in the last decade, availability, accessibility and affordability of electricity for all people is still a major challenge around the World. Despite Kenya having a Rural Electrification Programme the implementation of the Programme has been a challenge. Insufficient attention to rural electrification in the Kenya by the Government has contributed to the widening gap in electricity access between the rural population and urban population. The trend has occurred in almost all the Developing Countries where the respective governments have struggled with the issue of low electrification rates in their rural areas. Kieni East Sub County has had electrification projects being implemented since the rolling of the Rural Electrification Programme. In Kieni the Rural Electrification Programme seeks to facilitate competitive, client-friendly and development-oriented organization for financing and promoting projects covering power generation, power conservation, power transmission and power distribution network though the accessibility to electricity in the area still remains low. According to REA (2014) in the more than 4,000 households in Kieni East approximately 700 households are connected to electricity. The study was based on the following objectives: to establish the influence of funding on the implementation of rural electrification programme in Kieni East Sub County; to assess the influence of cost of electricity on the implementation of rural electrification programme in Kieni East Sub County; to determine the influence of alternative sources of power on the implementation of rural electrification programme in Kieni East Sub County; and to establish the influence of demand for electricity on the implementation of rural electrification programme in Kieni East Sub County. 


\section{Statement of the problem}

The Government of Kenya through the Kenya Rural Electrification Programme has played a crucial role in the provision of electricity to rural areas in a bid to spur human, social and economic development in the Country. However, the implementation of rural electricity programmes has been a challenge to the government with only $36 \%$ of the rural population having access to electricity (Republic of Kenya, 2013). There are various local studies done on rural electrification in Kenya. Dufe (2015) focused on accessibility to rural electrification in Naivasha, whereas Mwiti (2014) focused on the influence of rural electrification on poverty eradication. Research shows that in Nyeri County, Kieni East Sub County is the least beneficiary of the rural electrification programme having very few households connected to electricity compared to other Sub Counties in Nyeri County (Muturi, 2015). According to R.E.A (2014), despite access to electricity in Kieni standing at $46.7 \%$ the connectivity level was less than $20 \%$. The challenges in the implementation of the Rural Electrification Programme in Kieni East are the subject of this study. The researcher has identified a gap in knowledge and seeks to determine the factors influencing the implementation of rural electrification programme in Kenya, with a special focus on Kieni East Sub County in Nyeri County. The question is what are the factors influencing implementation of rural electrification programme in Kieni East Sub County?

\section{Theoretical Review}

The study is based on various theoretical foundations. The reviewed theories include stakeholder theory, theory of constraints and rational choice theory.

\section{Stakeholder theory}

Stakeholder Theory was advanced by Edward Freeman in 1994.The basic idea of stakeholder theory is that organizations have relationships with many constituent groups and that it can engender and maintain the support of these groups by considering and balancing their relevant interests (Kirsi, 2010). Kirsi (2010) further noted four premises of the stakeholder theory that; corporations have relationships with many constituent groups (stakeholders) that affect or are affected by its decisions, the theory is also concerned with the nature of these relationships in terms of both processes and outcomes for the firm and its stakeholders, that the interests of all (legitimate) stakeholders have intrinsic value and not one set of interests is assumed to dominate others, and finally the theory focuses on managerial decision making. Based on the argument of instrument of power of this theory, a company using stakeholder 
approach will have increased organizational performance in terms of economics and other criteria.

Kirsi (2010) noted that while having its origins in strategic management, stakeholder theory has been applied to a number of fields, presented and used in a number of ways that are quite distinct and involves very different methodologies, concepts, types of evidence and criteria of evaluation. Similarly,Lynda (2006) after examining stakeholder theory concluded that the support of key stakeholders was essential for project success and consequently the success of programs. In relation to the study the theory can be applied in that managers of REP should on the one hand manage the organization for the benefit of its stakeholders in order to ensure their rights and participation in decision making and on the other hand the management must act as the stakeholder's agent to ensure the survival of the Authority to safeguard the long term stakes of each group. The theory is relevant in that the stakeholders in the rural electrification should be involved in the implementation of the rural program. Where some stakeholders like the community are not involved the implementation of the program may be faced by hitches. The program should also benefit each and every stakeholder in order to enhance its implementation.

\section{Theory of Constraints}

Theory of constraints (TOC) began as a production scheduling aid, developed by Eliyahu Goldratt in the late 1970s, terming it as 'optimized production time table' and was quickly developed in to a software package commonly known as optimized production technology. Ten years later, due to failures caused by the expectations associated with a turnkey package led Goldratt and others to realize that what was needed was to convince people to change ways, rather than tailor the package to simply automate their old policies and procedure - changes to their thinking and actions were needed if the potential gains were to be realized (Ruhl, 1996).

Sebastiano and Ragnhild (2014), revealed that what is considered as a constraint in project management can be categorized in to four; as political constraints (such as defined vision, mission, scope of projects), technical constraints (such as competencies, technologies, existing infrastructure and natural conditions like geology, landscape and climate), social constraints (such as codes of conduct, organizational hierarchies, personal relationships and accepted/expected behaviors) and administrative constraints (such as budgets, project schedules, scope, written contractual agreements among others).

Theory of Constraints (TOC) challenges managers to rethink some of their fundamental assumptions about how to achieve the goals of their organizations, about what they consider productive actions, and about the real 
purpose of cost management. TOC emphasizes the optimization of performance within the defined set of constraints of the existing processes and product offerings. Therefore, the study identifying the factors influencing the implementation of rural electrification program can lead to developing necessary remedies for overcoming constraints created by such factors.

\section{Rational Choice theory}

Rational Choice Theory was advanced by George Homans in 1961 and is an economic theory that assumes that individuals always make prudent and logical decisions that provide them with the greatest benefit or satisfaction and that are in the best self- interest (Scott cited in Browning et al, 2010). Most mainstream economics and theories are based rational choice theory. Rational Choice theorists believe that most human decisions are based on maximizing a person's own benefits, while minimizing that which can hurt the individual.

Rational choice theory is a framework for understanding and often formally modeling social and economic behavior. It is the paradigm in the currently dominant school of microeconomics. Rationality is widely used as an assumption of the behavior of individuals in micro economic models and analysis which appears in almost all economics dealing with decisionmaking. Rational choice theory uses a specific and narrower definition of rationality, simply to mean that an individual act as if balancing costs against benefits to arrive at action that maximizes personal advantage (Scott,2000). In rational choice theory, the costs are only extrinsic to the individual rather than being intrinsic. This theory is relevant to the study in that it provides a basis for understanding the implementation of rural electrification in that the stakeholders have to make a decision on whether to implement the programme based on various factors.

\section{Literature review}

\section{Funding and implementation of rural electrification programme}

Barnes \& Foley (2009) revealed that the financial viability of electricity distribution utilities is governed by the balance of costs and revenues generated from sales of energy and the cost of providing service. Due to lower population density, often lower income, and concurrently lower specific energy consumption for rural communities, rural distribution systems realize far lower revenue per kilometer of rural distribution line than their urban counterparts. Moreover, Zhang \& Kumar (2011) observes that, rural distribution service providers are also faced with higher operating expenses per household or commercial consumer served, given their lower energy density. Additionally, rural electric service providers recruit management and staff resources from communities that often have fewer trained engineers, 
accountants, financial specialists, and customer service specialists due to lower levels of professional and practical skills training. In short, the business of rural electrification provides few financial incentives for distribution service providers, while presenting significantly higher risks than those faced by urban distribution service providers (Barnes \& Floor, 2006).

The emerging of power sector reforms such as commercialization, structural changes and privatization, and the relative success of the reforms in pioneer Countries stimulated adoption of similar reforms in many Countries (Wamukonya, 2003). Further, financing institutions such as the World Bank believed that the reforms could help improve technical and financial performance of the power sector and as such, started incorporating conditions for reforms in lending agreements (World Bank, 2010).

South Africa instituted an electrification programme that was funded mainly through cross subsidies and a consumer levy by the country's main utility, Eskom and the municipalities (Philpott \& Clark, 2002). The National Electricity Regulator (NER) was responsible for management and administration of the RE fund and allocated subsidies to electrification concessionaires, set prices and regulated the performance of the companies. With this approach, South Africa was able to increase the level of access to electricity from $40 \%$ in 1994 to $66 \%$ (46\% rural, 79\% urban) in 2002. In other African Countries, RE was mainly financed by government subsidies. However, increased donor support was experienced in many African Countries such as Uganda and Zambia following reforms. With support from the Swedish Agency for International Development (SIDA), Zambia established some Energy Services Companies (ESCOs) that supplied electricity to selected rural areas using solar PV systems (SEI, 2001).

Funding plays a great role in the formulation of Renewable Energy Technologies (RETs) policies. Majority of advanced and electric RETs are not affordable to most of the population in Africa who are poor, with poverty degrees of between 50 to $70 \%$ (UNDP, 2009). This is true particularly for RETs that have huge cost of imported parts, than those that can be locally produced and assembled utilizing locally available parts. The RETs with huge cost of importing parts put an extra burden on foreign exchange reserves of African economies, which are frequently little and approaching exhaustion, and needs expensive funding strategies and huge subsidies (Karekezi \& Kithyoma, 2003). The subsidies are unsustainable in the long term, except when the technologies given are planned to include income generation.

\section{Cost of electricity and implementation of rural electrification programme}

According to Schillebeeckx, Priti, Rahul and Gerard (2013), affordability of rural electrification program is determined by the capital cost 
and periodic payments further noting that in Bolivia a small grid doubled its connections by spreading the connection charges over 5 years while Malawi Electricity Company which demanded full upfront payment of 30 years cost of line extension resulted in a $2 \%$ rural electrification rate. In Thailand, electricity related materials were standardized and manufactured locally, reducing procurement and transportation costs (Pellegrin \& Tasciotti, 2012).

House wiring, connection charges and power tariff are a major constraint to the poor in accessing electricity. Cook (2013) revealed that the issues to addressing access of electricity to the poor have been addressed through ensuring that first, service providers provide access, the second instrument is required to reduce connection costs through tariff design or direct subsidies built in payment plan favoring the poor and third is to increase range of service providers to avail consumers with choice. Cook (2013) further indicated that achievement is difficult and slow and understanding of the issues that act as constraints are incomplete.

\section{Alternative sources of power and implementation of rural electrification programme}

Kenya is endowed with a significant amount of alternative power sources which includes biomass and biogas among others. Solar and wind are readily available with significant access of both rural and urban population (Jacobson, 2004). The affordability of the alternative sources of power is linked to the economic income of the population. In the upcountry, most people are able to afford biomass energy that is derived from woodlands, farm lands, bush lands, closed forests, plantations, industrial and agricultural residues. The forests provide over $45 \%$ of the biomass energy that is the largest means of alternative energy used in Kenya - both rural and urban areas. Solar and wind are also affordable compared to other sources of power like nuclear, fossil, coal, hydro and liquefied petroleum gas. A small section of the population uses hydro power and diesel fueled power.

The reliability of the alternative sources of power is based on the individual source of power. Hydro and diesel fueled power are unreliable because of the availability of diesel fuel in some areas where there is scarcity of fuel and hoarding by the dealers awaiting price increase to maximize profit. The wear and tear of the diesel generators affects its reliability. Biomass energy, solar and wind are reliable for a significant number of people across the Country. It has got less of other related costs compared to the diesel fuel generators (KIPPRA, 2007). Preference to most of the people is the biomass and solar. The availability of trees especially in rural areas motivates people to use the biomass energy sources like wood. Solar is readily available in the Country with minimal related costs for buying and maintaining solar panels. 


\section{Demand for electricity and implementation of rural electrification programme}

Rural households not only have limited access to modern energy sources but also have low demand for it due to high cost associated with electricity including connection fee and monthly charges compared to alternative fuel sources that are easily accessible due to low cost of connection and maintenance. For both electrified and non-electrified households, the three fuel sources: firewood, charcoal and kerosene represent a major proportion of their usage and some use solar energy. However, in comparative terms these three fuel sources take up $98 \%$ of the non-electrified total energy expenses, whereas the figure is $65 \%$ for their electrified counterparts. This means that the non-electrified households are spending considerably more on these traditional fuels than electrified households. One way of reducing the consumption of these fuels by the non-electrified is to provide them with electricity (Eberhard \& Gratwick, 2005).

Rural areas have three categories of energy use: household energy, agricultural energy and energy for small/micro enterprises this influence the demand for the electricity. Despite the demand of electricity in rural areas, the generation of electricity remains low in Developing Countries leading to insufficient supply of generation that does not match with the demand for electricity.(Pellegrin \& Tasciotti,2012).The attitude that rural people have that they cannot afford electricity and electricity is expense cause them to have low demand for electricity and turn to other sources of energy which includes solar,wood,kerosene and biogas among others (Jacobson, 2004).

\section{Research Methodology}

The study adopted a descriptive research design. The target population of the study was 4,289 households in Kieni East Sub County The study used Fisher, Laing and Stoeckel (1983) formula to sample 94 households. Simple random sampling was used in selecting the 94 households who were used in the study. Purposive sampling approach was used to select 5 REA officials and the 94 respondents who were involved in the study. A questionnaire was used to collect data from the household members and interviews for the REA officials. Descriptive and inferential statistics were used to analyze quantitative data from the households. The data was presented in form of graphs and charts. Multiple regression was used for inferential statistics analysis.

The regression model adopted was captured below:

Where:

$$
Y=\beta_{0}+\beta_{1} X_{1}+\beta_{2} X_{2}+\beta_{3} X_{3}+\beta_{4} X_{4+} \varepsilon
$$

$\mathrm{Y}=$ Implementation of REP 
$\mathrm{X}_{1}=$ Funding

$\mathrm{X}_{2}=$ Cost of electricity

$\mathrm{X}_{3}=$ Alternative source of power

$\mathrm{X}_{4}=$ Demand

$\beta_{1}, \beta_{2}, \beta_{3}$ and $\beta_{4}$ are the variable coefficients

$\varepsilon$ is the error term.

Qualitative data was analyzed using content analysis where the data was grouped into themes based on the objectives of the study. The data was presented in prose form.

\section{Findings}

From the research it was established that $62.4 \%$ of the respondents were male. $41.2 \%$ of the respondents indicated that they were aged 51-70 years, $32.9 \%$ indicated $31-50$ years, $15.3 \%$ indicated above 70 years, $5.9 \%$ indicated 21-30 years whereas $4.7 \%$ indicated below 20 years. $45.9 \%$ indicated their highest education as secondary, 25.9\% indicated primary, 20\% indicated post-secondary whereas $8.2 \%$ had no education. $48.2 \%$ of the respondents indicated that they had lived in the area for 6-10 years, 36.5\% indicated more than 10 years, $11.8 \%$ indicated $2-5$ years whereas $3.5 \%$ indicated less than 2 years. $56.5 \%$ of the respondents indicated that they were married, $27.1 \%$ indicated that they were single, $8.2 \%$ indicated widowed, $5.9 \%$ indicated separated whereas $2.4 \%$ indicated that they were divorced.

The study established that majority of the respondents as shown by $70.6 \%$ agreed that funding influenced the implementation of REP in Kieni East. On the sources of funding majority as shown by $84.7 \%$ of the respondents indicated that they sourced their funds from bank loans. Other sources included family and friends; savings; government subsidies; SACCOs and grants. Majority of the respondents as shown by $81.2 \%$ indicated that cost of electricity affected the implementation of REP. Majority of the respondents as shown by $81.2 \%$ indicated that alternative power affected the implementation of REP. $78.8 \%$ of the respondents indicated that they sourced their power from charcoal. Other sources indicated were firewood, paraffin, biogas, solar, plastics, banana trees, and grass. The established regression equation was:

$$
Y=2.231+0.962 X_{1}+0.473 X_{2}+0.312 X_{3}+0.824 X_{4}
$$

The above regression equation implies that by taking all the independent constant rural electrification programme implementation will change by 2.231 . The findings also indicated that by taking a unit increase in funding leads to an increase in REP implementation by 0.962 all other factors held constant; a unit increase in cost of electricity leads to an increase in REP implementation by 0.473 all other factors held constant, a unit increase in 
alternative sources of power leads to an increase in REP implementation by 0.312 all other factors held constant and a unit increase in demand for electricity leads to an increase in REP implementation by 0.824 all other factors held constant. All the variables were found to be significance since their p-value were less than 0.05 indicating that the entire variables were statistically significant. The findings are tabulated in table 2 below.

Table 2: Regression coefficients

\begin{tabular}{|c|c|c|c|c|c|c|}
\hline \multicolumn{2}{|c|}{ Model } & \multicolumn{2}{|c|}{$\begin{array}{l}\text { Unstandardized } \\
\text { Coefficients }\end{array}$} & \multirow{2}{*}{ 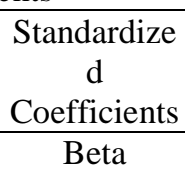 } & \multirow[t]{2}{*}{$\mathrm{T}$} & \multirow[t]{2}{*}{ Sig. } \\
\hline & & B & Std. Error & & & \\
\hline \multirow[t]{6}{*}{1} & (Constant) & 2.231 & .141 & 2.131 & 4.023 & .025 \\
\hline & Funding & .962 & .056 & .176 & 2.332 & .022 \\
\hline & Cost of electricity & .473 & .064 & .341 & 3.564 & .036 \\
\hline & $\begin{array}{c}\text { Alternative sources of } \\
\text { power }\end{array}$ & .312 & .141 & .216 & 4.217 & .017 \\
\hline & Demand & .824 & .211 & .371 & 2.578 & .023 \\
\hline & \multicolumn{6}{|c|}{ a. Dependent variable: Implementation of REP } \\
\hline
\end{tabular}

\section{Conclusions and recommendations}

The study concludes that funding is very important since it influence the implementation of REP in Kieni East to a great extent. The cost of electricity affects the implementation of REP in Kieni East to a great extent. The cost of electricity in Kieni East is high and reflected in connection costs, cost of electric lighting appliances, cost of electrification and periodic payments to Kenya power. Despite there being various sources of power in Kieni East, charcoal is the main source. Alternative power affects the implementation of REP in Kieni East to a great extent and this shows that these alternatives do hold water when it comes to REP implementation. The researcher further concludes that there is sufficient awareness on the alternative sources of power to electricity in Kieni East and the households in Kieni East use other sources of power as they are accessible, cheaper and more reliable compared to electricity. The demand for electricity affected the implementation of REP in Kieni East to a great extent. Although, there is low level of community participation in REP in Kieni East with inadequate awareness, but the attitude towards electrical power and the need for electricity remains positive and high. The demand for electricity in Kieni East is high with many households and businesses not connected to electricity. The REP has existed in Kieni East for less than 10 years. However, the REP in Kieni East has been implemented to a low extent. Despite the increased connectivity, poor maintenance of electrical facilities together with the distance from the main grid has hindered the implementation of the REP in Kieni East. 
The study recommends that the Government should subsidize on the consumer connections cost, domestic house wiring material cost and the unit cost of energy. In order to create a sense of ownership and ensure sustainability of the REPs, project implementers need to build in community participation in their project designs, implementation and other decision-making processes.

The government needs to support and provide incentives for investments in alternative power sources. These needs to be seen as complementing REA's efforts to improve and increase accessibility while at the same time promoting the use of renewable energy as opposed to fossil generated electricity.

The study further recommends that the Government should allocate sufficient funds and ensure timely disbursement for implementation of grid extension and generation projects in a coordinated manner. Therefore, more programme funders should be identified. the study suggests that further studies should be carried out on the influence of institutional factors on the implementation of rural electrification programs in Kenya.

\section{References:}

1. Abdullah, S., \& Markandya, A. (2007). Electrification projects in Rural Kenya: evaluation study. U. K.: Department of Economics, University of Bath.

2. Barnes, D., \& Foley, G. (2009). Rural Electrification In: The Developing World: A summary of lessons from successful programs. UNDP/World Bank Energy Sector Management Assistance Programme (ESMAP), World Bank, Washington, DC.

3. Brian,M. (2013). Analyzes of Electricity Transformer vandalism in Nakuru and Murang'a Counties. Masinde Muliro University.

4. Cecelski, E., \& Ounalli, A. (2012). Low-cost Electricity and Multisector Development in Rural Tunisia. Sub-Saharan Africa: Introducing Lowcost Methods in Electricity Distribution Networks, 183.

5. Cook, P. (2013). Rural Electrification and Rural Development. University of Manchester.

6. Dufe, E. M. (2015). Factors influencing accessibility of rural electrification in Kenya: a case of Naivasha constituency (Unpublished Thesis). University of Nairobi, Kenya.

7. Fisher, A., Laing, J., \& Stoeckel, J. (1983). A handbook for research design. New York: The population Council.

8. Goldratt, E. M. (2001). Essays on the Theory of Constraints. Great Barrington, MA, North River Press.

9. IEG. (2008). The Welfare Impact of Rural Electrification: A Reassessment of the Costs and Benefits. Washington, The Independent Evaluation Group, The World Bank Group. 
10. Karekezi, S., Kimani, J., Mutiga, A., \& Amenya, S. (2011). The Impact of Power Sector Reforms on the Poor in Eastern Africa, AFREPREN/FWD Secretariat working paper 317.

11. Katie, A. (2010). Rural Electrification in Oregon 1930-1955. (Thesis). Department of History Linfield College.

12. Kirsi, A. (2010). Stakeholder Management in International Projects. Aolto University, doctoral dissertation series 2010/13.

13. Ministry of Energy (2013). Rural Electrification in Kenya. Sessional Paper No. 4 on Energy.

14. Muturi, P. (2015). A Review of Nyeri County -Kenya Strategic Plan 2013-2017.International Journal of Economics, Commerce and Management. 3(5), 1234-1249.

15. Mwangi, C. I., \& Ngugi, K. (2014). Determinant of Regulations on Growth of Electricity Projects in Kenya: A Case Study of Rural Electrification Authority. European Journal of Business Management, 1 (11), 336-352.

16. Mwiti, A. M. (2014). Influence of rural electrification on poverty eradication: a case of Tigania West Constituency, Meru County, Kenya. Unpublished Thesis, University of Nairobi, Nairobi, Kenya.

17. Ogalo, K. (2011). Factors influencing electricity distribution in Nyamarambe Division; Kisii County, Kenya (Unpublished Thesis). University of Nairobi, Kenya.

18. Pellegrini, L., \& Tasciotti, P.(2012). Rural Electrification now and then: Comparing contemporary challenges in developing countries to the USA's experience in retrospect. Forum for Development Studies, 1-24.

19. Philpott,J., \& Clark ,A. (2002). South Africa: Electricity Reform with a Human Face. In Dubash Navroz K. (eds). World Resources Institute. Washington DC, USA.

20. Republic of Kenya (2013). Energy Sector Strategy. Rural Energy Task Force Final Report, Nairobi.

21. Sanghvi, A., \& Barnes, D. (2011). Rural electrification: Lessons learned. World Bank Findings: Operational Quality and Knowledge Services, Africa Region Infrastructure. World Bank, Washington, DC.

22. Sebastiano, L., \& Ragnhild, K. (2014). Constraint-Shattering Practices and Creative Action in Organizations. Organization Studies, 35(4), $587-$ 611. 